\title{
Variation of tropical cyclone activity in the South Indian Ocean: El Niño-Southern Oscillation and Madden-Julian Oscillation effects
}

\author{
Chang-Hoi Ho, ${ }^{1}$ Joo-Hong Kim, ${ }^{1}$ Jee-Hoon Jeong, ${ }^{1}$ Hyeong-Seog Kim, ${ }^{1}$ \\ and Deliang Chen ${ }^{2,3}$ \\ Received 12 March 2006; revised 20 June 2006; accepted 1 August 2006; published 16 November 2006
}

[1] The present study examines variation of tropical cyclone (TC) activity in the South Indian Ocean (SIO) during TC seasons (December-March) for the period 1979-2004. The impact of the El Niño-Southern Oscillation and the Madden-Julian Oscillation (MJO) on the variation is revealed through a composite analysis. During El Niño periods TC genesis was shifted westward, enhancing the formation west of $75^{\circ} \mathrm{E}$ and reducing it east of $75^{\circ} \mathrm{E}$. These changes in the genesis correspond to a westward shift of convection. It may be explained by a remote effect on the SIO; that is, the increase in sea surface temperature in the central eastern Pacific alters the Walker circulation and forms an anomalous anticyclonic circulation in the east SIO during E1 Niño. The spatial difference in TC passages between El Niño and La Niña shows a significant decrease to the southeast of Madagascar but a moderate increase in the central midlatitude SIO, indicating that TCs move farther east during El Niño. This change is possibly due to the anomalous southwesterlies east of Madagascar. Variation of TC activity also depends on various MJO phases: frequent TC passages for phases $2-4$ (strong convective activity straddles along the equatorial Indian Ocean) versus infrequent TC passages for other phases. TC tracks tend to be more south oriented in phase 3 compared with those in phases 2 and 4 . This is possibly caused by the increased steering northerlies which are a part of the anticyclonic Rossby wave of Gill type in response to the suppressed MJO-related convection in the maritime continent.

Citation: Ho, C.-H., J.-H. Kim, J.-H. Jeong, H.-S. Kim, and D. Chen (2006), Variation of tropical cyclone activity in the South Indian Ocean: El Niño-Southern Oscillation and Madden-Julian Oscillation effects, J. Geophys. Res., 111, D22101, doi:10.1029/2006JD007289.

\section{Introduction}

[2] Tropical cyclone (TC) activity fluctuates depending on large-scale environmental changes caused by various atmospheric and oceanic oscillatory phenomena. Among many factors that modulate the variation of TC activity, El Niño-Southern Oscillation (ENSO) and the MaddenJulian Oscillation (MJO) are known as the most dominant modes overwhelming tropical low-frequency variability [e.g., Neelin et al., 1998; Zhang, 2005]. It is established that ENSO and the MJO are linked to changes in sea surface temperature (SST), tropical convection, and large-scale atmospheric circulation over vast tropical oceans on interannual and subseasonal timescales, respectively. In various tropical ocean basins, numerous studies have documented the ENSO-TC [e.g., Gray, 1984; Chan, 1985; Chu and Wang, 1997; Landsea,

\footnotetext{
${ }^{1}$ School of Earth and Environmental Sciences, Seoul National University, Seoul, Korea.

${ }^{2}$ Earth Sciences Centre, Gothenburg University, Gothenburg, Sweden.

${ }^{3}$ Also at Laboratory for Climate Studies/National Climate Center, China Meteorological Administration, Beijing, China.
}

Copyright 2006 by the American Geophysical Union. 0148-0227/06/2006JD007289\$09.00
2000; Wang and Chan, 2002] and MJO-TC relationship [e.g., Liebmann et al., 1994; Maloney and Hartmann, 2000a, 2000b; Hall et al., 2001]. In particular, the ENSO-TC relationships over global tropical oceans except for the Indian Ocean are well summarized by $C h u$ [2005].

[3] ENSO influences SST and overlying convection and atmospheric circulations over the tropical Indian Ocean [e.g., Lau and Nath, 2003; Yoo et al., 2006]. During El Niño, overall SSTs of the Indian Ocean are increased associated with a weaker surface wind speed, i.e., reduced latent and sensible heat release from the ocean surface [Yoo et al., 2006]. Changes in convection and atmospheric circulations are also suggested by Lau and Nath [2003] and Yoo et al. [2006]: the development of an anticyclonic (cyclonic) anomaly in the lower troposphere over the central east subtropical South Indian Ocean (SIO; central west midlatitude SIO). While ENSO has strongest variability in the Pacific, the MJO activity is strongest in the Indian sector. Thus a slow eastward propagating convective anomaly and a coherent circulation anomaly related to the MJO also significantly modulate the Indian Ocean weather and climate systems in many respects [Hartmann and Michelsen, 1989; Wang and Rui, 1990]. 


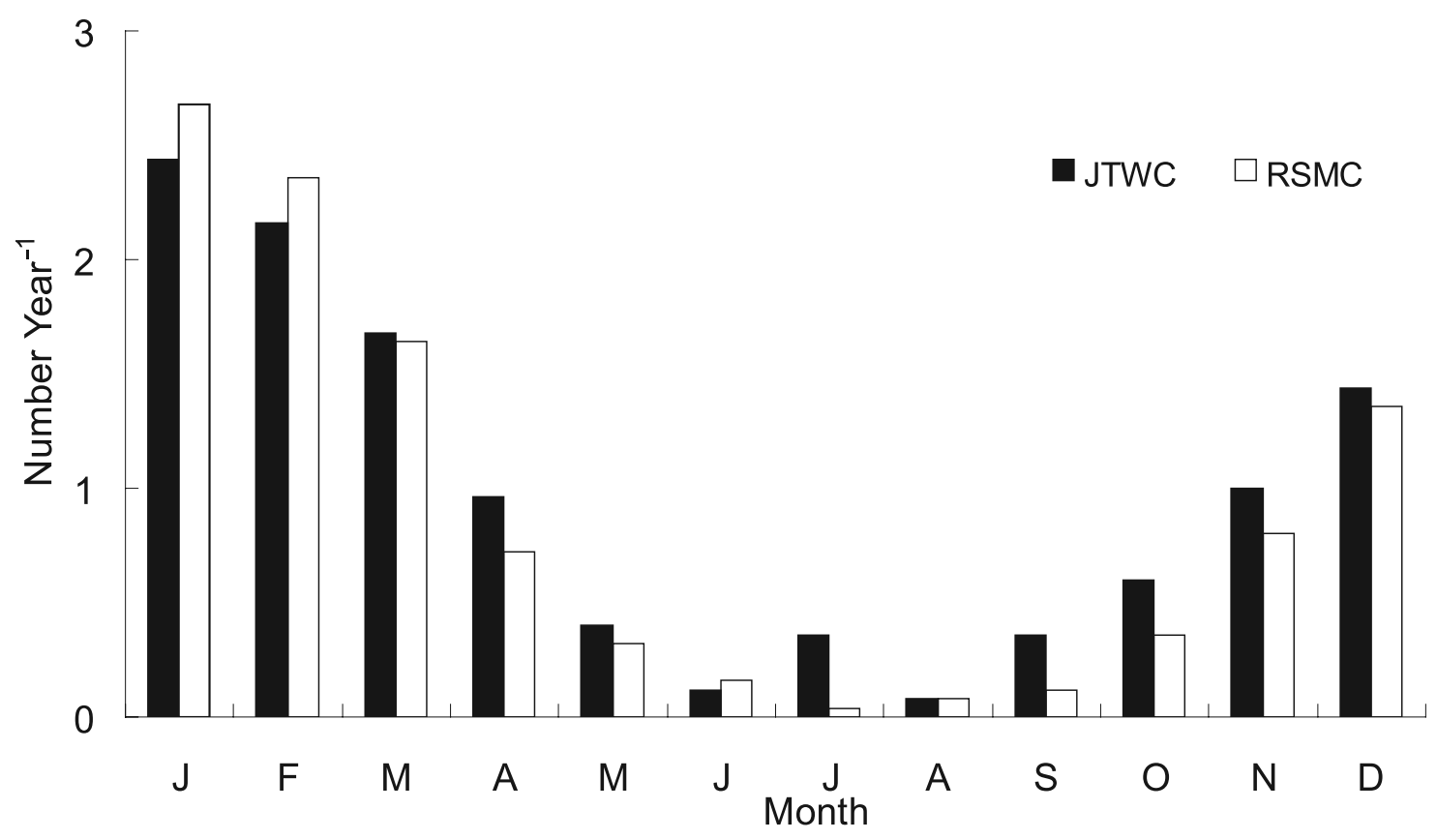

Figure 1. Number of TCs formed each month in the South Indian Ocean for the period 1979-2004. JTWC denotes data archives from the Joint Typhoon Warning Center, and RSMC denotes the La Reunion Regional Specialized Meteorological Centre.

[4] Similar to TCs which appeared in other tropical ocean basins, the TCs in the SIO also cause tremendous social and economic damage in southeast Africa and the island of Madagascar. There are about 12 TCs in the SIO every year (see Figure 1). Most of them originate from the east of Madagascar $\left(50^{\circ}-100^{\circ} \mathrm{E}, 5^{\circ}-15^{\circ} \mathrm{S}\right)$ and some from the Mozambique Channel during the warm season in the Southern Hemisphere. Several attempts have been made to characterize TC activity in this oceanic area associated with ENSO [e.g., Jury, 1993; Jury et al., 1999; Xie et al., 2002; Kuleshov, 2003; Kuleshov and de Hoedt, 2003], convectively coupled equatorial waves including the MJO [e.g., Bessafi and Wheeler, 2006], and the stratospheric quasi-biennial oscillation (QBO) [e.g., Jury, 1993; Jury et al., 1999]. Jury [1993] found that the frequency of TC genesis in the western SIO increases during the east phase of QBO, but the impact of ENSO is not significant because of increased upper westerly shear, in spite of convection being enhanced during El Niño summers. Xie et al. [2002] also examined TC day in the western SIO with respect to in situ thermocline variability and found that number of TC day is greatly increased in the offshore east of Madagascar. A most recent document about the ENSO-TC relationship by Kuleshov and de Hoedt [2003] demonstrated that TC numbers were increased between $85^{\circ} \mathrm{E}$ and $105^{\circ} \mathrm{E}$ during $\mathrm{La}$ Niña years compared to El Niño years. Bessafi and Wheeler [2006] found that the MJO extensively modulates low-level vorticity and vertical wind shear and further modulates the number of TCs. When a convection center is located in tropical east Indian Ocean, enhanced cyclonic vorticity anomalies prevail in the equatorial Indian Ocean and the zero wind shear line moves poleward, suggesting enhanced TC genesis, as compared with the times when a convection center is located in the Western Hemisphere and Africa.
[5] On the basis of the researches mentioned above, there is general agreement over the impact of ENSO on the frequency of TC genesis in the SIO, but its influence on the spatial distribution of TC occurrence (e.g., genesis location and their tracks) in the SIO remains to be investigated. Moreover, although Bessafi and Wheeler [2006] examined the MJO-TC relationship, their analysis is confined to TC genesis only. Therefore further investigation on $\mathrm{TC}$ tracks associated with the MJO is required. The focus of this paper is on the impacts of ENSO and the MJO on the TC genesis and passage in the SIO. Another distinction of this study is the data set used. Bessafi and Wheeler [2006] used the archive of the La Reunion Regional Specialized Meteorological Centre (RSMC), but the present study utilized the records of the Joint Typhoon Warning Center (JTWC).

[6] This paper is organized into 4 sections as follows. Section 2 describes the data sets used, definition of TCs, ENSO and categorization of the MJO phase. A brief comparison of seasonal variation of TC genesis between RSMC and JTWC is also given in this section. Section 3 discusses the main results that include effects of ENSO and the MJO on the variability of the TC geneses and tracks in the SIO. Finally, the summary and discussion are presented in section 4 .

\section{Data and Analysis Methods}

\subsection{Data}

[7] This study has examined TC best track data taken from the JTWC in the SIO for the period 1979-2004 (available online at https://metoc.npmoc.navy.mil/jtwc. $\mathrm{html}$ ). The JTWC primarily uses the Dvorak method to determine TC intensity, which analyzes cloud patterns in 
visible and infrared images from both polar orbiting and geostationary satellites. Each best track data contains TC center locations and intensities (minimum pressure and maximum wind speed) at 6-hour intervals. In the present study, TCs are defined when the maximum wind speed $\left(v_{\max }\right)$ sustained for a $1-$ min period is greater than $17 \mathrm{~m} \mathrm{~s}^{-1}$. Hence the TCs studied here are strong systems including tropical storms $\left(17 \mathrm{~m} \mathrm{~s}^{-1}<v_{\max } \leq 24 \mathrm{~m} \mathrm{~s}^{-1}\right)$, severe tropical storms $\left(24 \mathrm{~m} \mathrm{~s}^{-1}<v_{\max } \leq 32 \mathrm{~m} \mathrm{~s}^{-1}\right)$, and severe tropical cyclones $\left(v_{\max }>32 \mathrm{~m} \mathrm{~s}^{-1}\right.$; these are referred to as hurricanes or typhoons in other ocean basins). In another TC data set from the archive of the La Reunion RSMC, TC is defined as when its system reaches $v_{\max } 30$ knots and a center pressure of less than $1000 \mathrm{hPa}$ [Bessafi and Wheeler, 2006].

[8] We have compared climatological features of these two TC data sets prior to a further analysis. Figure 1 depicts the monthly number of TCs averaged for the 1979-2004 period. Generally, the two data show a consistent seasonal distribution with similar TC numbers. More than 2 TCs per month are generated in the months of January and February, 1-2 TCs for March and December, 0.7-1 TCs for April and November, and few TCs (averages of less than 0.5 per month) in the remaining months. As a summary of these TC statistics, two thirds of the total TCs formed over the region are observed in an austral summer season (December through March). Consequently, 25 austral summers of JTWC from $1979 / 80$ to $2003 / 04$ have been selected to be analyzed in this work.

[9] The present study has also investigated SST, outgoing longwave radiation (OLR), horizontal winds at tropospheric levels $(850 \mathrm{hPa}$ through $200 \mathrm{hPa}), 850-\mathrm{hPa}$ vorticity, and vertical zonal wind shear in order to examine related thermodynamic and dynamic fields in connection with variation of TC activity. The daily SST has been obtained on the basis of weekly optimally interpolated SST archive data at the National Centers for Environmental Predictions (NCEP) with a horizontal resolution of $1^{\circ} \times 1^{\circ}$ latitude by longitude [Reynolds and Smith, 1994]. The daily OLR has been taken from the NOAA Web site (http://www.cdc.noaa. gov). The daily horizontal wind and vorticity are obtained from the NCEP/National Center for Atmospheric Research (NCAR) reanalysis. The horizontal resolution of OLR, wind, and vorticity is $2.5^{\circ} \times 2.5^{\circ}$ latitude by longitude.

\subsection{Analysis Methods}

[10] In this subsection, definition of ENSO, categorization of the MJO phase, and the method of significance testing are addressed. El Niño (La Niña) periods are defined when Nino 3.4 SST anomalies (SST anomalies averaged over $120^{\circ}-170^{\circ} \mathrm{W}, 5^{\circ} \mathrm{S}-5^{\circ} \mathrm{N}$ ) are greater (smaller) than $+0.5(-0.5)^{\circ} \mathrm{C}$. During the 25 austral summers, there are 7 El Niño periods: 1982/83, 1986/87, 1987/88, 1991/92, 1994/95, 1997/98, and 2002/03, and 8 La Niña periods: 1983/84, 1984/85, 1985/86, 1988/89, 1995/96, 1998/99, $1999 / 2000$, and 2000/01. The selected years are always qualified for the given criteria during the four austral summer months.

[11] To categorize the phase and amplitude of the MJO, the methodology of Wheeler and Hendon [2004] has been adapted. This method is developed on the basis of the empirical orthogonal function (EOF) analysis of equatori- ally averaged $\left(15^{\circ} \mathrm{S}-15^{\circ} \mathrm{N}\right)$ daily zonal wind at 850 and $200 \mathrm{hPa}$ and satellite retrieved OLR. Projection of daily observed data onto the multiple-variable leading two EOFs, yields a pair of normalized principle component time series, and the lead lag behavior of these time series provides the geographical distribution of the MJO phase. In the present study, the MJO phase is divided into 8 phases: phases 8 and 1 show that the center of convective activity is located over the Western Hemisphere/Africa, phases 2 and 3 the Indian Ocean, phases 4 and 5 the maritime continent, and phases 6 and 7 the western Pacific. The amplitude of the MJO is defined by the square root of the summation of squared principle components.

[12] The statistical significance may be tested by applying the $t$ statistic. However, there is an uncertainty of the sampling distribution as well as too small sampling size (i.e., 7 for El Niño years and 8 for La Niña years) when the difference in TC genesis and passage number between El Niño and La Niña is evaluated. For this reason, a nonparametric test is used instead of the $t$ test. The test applied in this study is the Mann-Whitney $U$ test. Its null distribution approximately follows the Gaussian distribution. More detailed information about this method is described by Chu and Chen [2005].

\section{Results}

\subsection{ENSO Effect}

[13] Figure 2 shows the austral summer climatology of TC genesis and TC passage number within each $5^{\circ} \times 5^{\circ}$ latitude-longitude grid box in the SIO. Their differences between El Niño and La Niña periods are also presented in Figure 2. Most of the TCs originate from the tropical SIO $\left(50^{\circ}-100^{\circ} \mathrm{E}, 5^{\circ}-15^{\circ} \mathrm{S}\right)$ and a few from the Mozambique Channel (Figure 2a). In particular, an average of one $\mathrm{TC}$ in every two years has formed within each $5^{\circ} \times 5^{\circ}$ grid in a contracted area, $65^{\circ}-80^{\circ} \mathrm{E}, 10^{\circ}-15^{\circ} \mathrm{S}$. It is noted that some of TCs generated in the Mozambique Channel are redeveloped TCs in warm ocean after they strike Madagascar and are weakened (figure not shown).

[14] To represent spatial distribution of TC activity, the 6-hourly positions of tracks are converted to gridded passage data; each 6-hourly TC position is binned into the corresponding $5^{\circ} \times 5^{\circ}$ grid box (Figure $2 b$ ). On the whole, TCs developed in the tropical SIO tend to move west and southwest around the northwestern flank of the South Indian subtropical high. On average, numbers of the seasonal mean TCs, which entered the $5^{\circ} \times 5^{\circ}$ grid boxes are up to 2 in the central west tropical SIO and about 1.5 in the island of Madagascar and neighboring oceans every year.

[15] The differences of the 4-month accumulated TC genesis and TC passage number between El Niño and La Niña (El Niño minus La Niña) are shown in Figures 2c and $2 \mathrm{~d}$, respectively. The difference of TC genesis location (Figure 2c) demonstrates an obvious east-west dipole structure: TC numbers increase in the western half of the SIO (west of $75^{\circ} \mathrm{E}$ ) and decrease in the eastern half of the SIO (east of $75^{\circ} \mathrm{E}$ ) during El Niño compared to La Niña. Similar east-west dipole pattern has been documented by Kuleshov and de Hoedt [2003]. However, they noted a border longitude, $85^{\circ} \mathrm{E}$, to the east-west dipole pattern, but this study indicates $75^{\circ} \mathrm{E}$. This discrepancy may arise from 


\section{Climatology}

a) Genesis

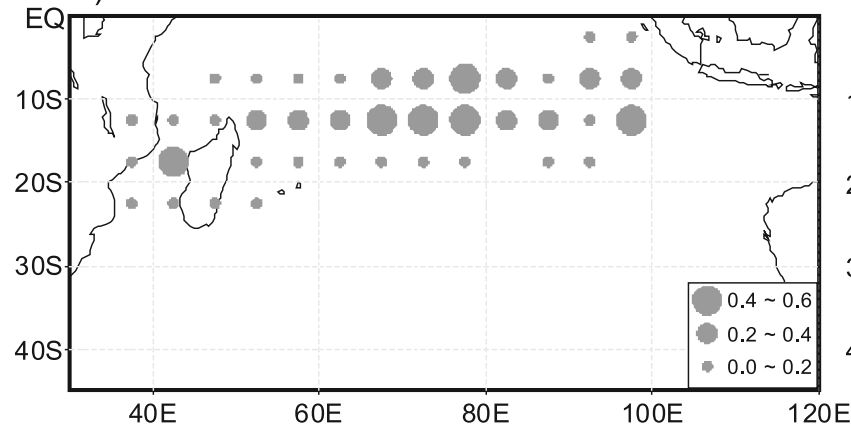

b) Passage

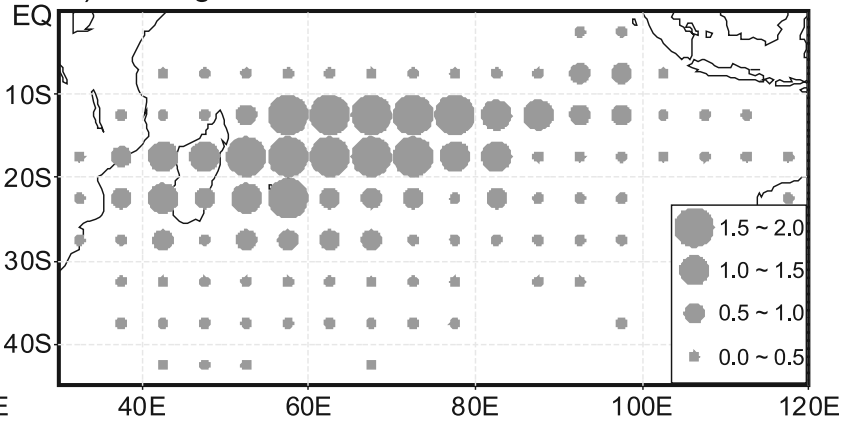

El Nino minus La Nina

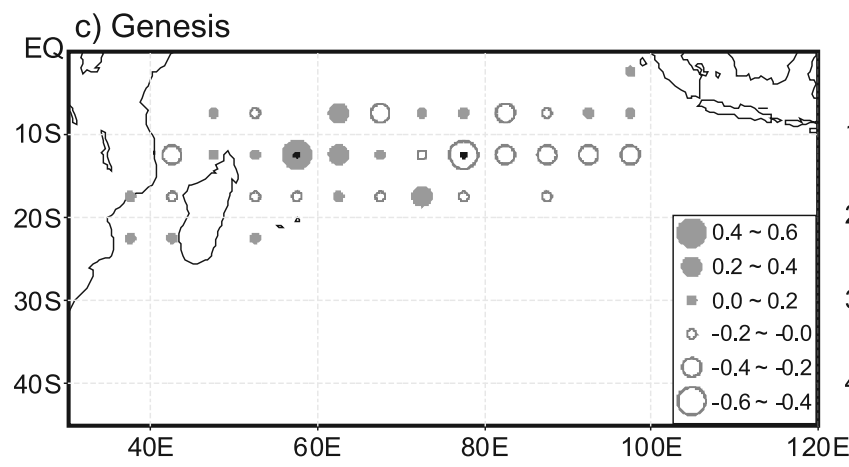

d) Passage

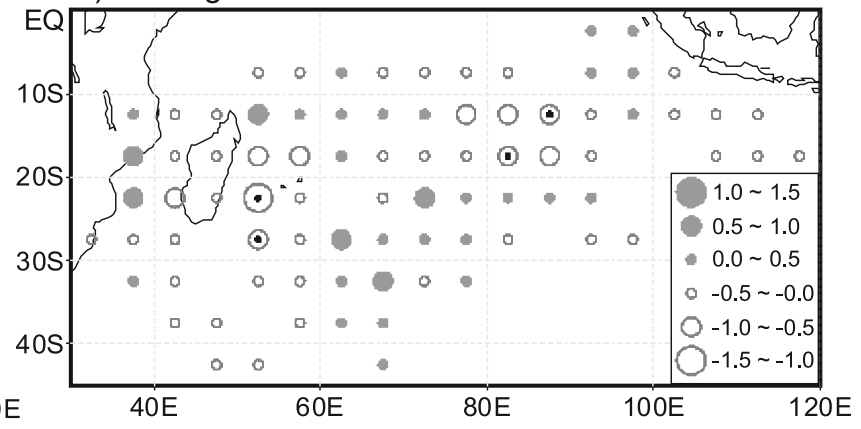

Figure 2. Climatological distribution of the austral summer, accumulated from December through March, for (a) TC genesis and (b) passage number per year in each $5^{\circ} \times 5^{\circ}$ longitude-latitude grid box and the difference of (c) genesis and (d) passage number between El Niño and La Niña. Black dots indicate that the differences are significant at the $95 \%$ confidence level using the nonparametric ManWhitney test. See the text for the definition of El Niño and La Niña periods.

different usage of the data period (1969-1999 versus 1979-2004). The large increase of the TC genesis number in the northeast of Madagascar is also consistent with the previous report by Xie et al. [2002]. This relation between ENSO and the location of genesis may be understood by changes in SST, convection activity, and large-scale circulations. This will be discussed later (see Figure 3).

[16] The difference in the number of TC passages changes its sign with alternating negative and positive patches from the Mozambique coastal region to the offshore southwest of Sumatra through the central midlatitude SIO (Figure 2d). TC passages increase in the Mozambique coastal region and the central midlatitude SIO $\left(60^{\circ}-80^{\circ} \mathrm{E}\right.$, $\left.20^{\circ}-40^{\circ} \mathrm{S}\right)$, but decrease in the southeast of Madagascar and the central east tropical SIO $\left(75^{\circ}-90^{\circ} \mathrm{E}, 10^{\circ}-20^{\circ} \mathrm{S}\right)$. Owing to small number of years, only four grid boxes where the TC passages decrease satisfy the statistical significance at the 95\% confidence level. However, the increase as well as the decrease corresponds to about $100 \%$ fluctuation from climatology (Figure 2d versus Figure 2b).

[17] Furthermore, the aforementioned changes in TC activity in the SIO may be attributed to the inclusion of weak intensity systems $\left(v_{\max } \leq 32 \mathrm{~m} \mathrm{~s}^{-1}\right)$ that are counted as TCs. It is known that ENSO increases SSTs in warm phase in the central SIO. However, destructive TCs of category 3 and higher $\left(v_{\max }>32 \mathrm{~m} \mathrm{~s}^{-1}\right)$ may be suppressed via vertical westerly wind shear and reduced upper anticyclonic vorticity that are produced during El Niño years
[Jury, 1993]. The authors confirmed the difference of TC passage number between El Niño and La Niña and also found that suppressed activity of intense TCs during El Niño (figure not shown).

[18] To elucidate changes in TC genesis and passage number in detail, patterns of the difference in some thermodynamic and dynamic variables are examined in Figure 3. As seen in Figure 3a, the entire tropical SIO shows a distribution of increased SSTs, with a maximum $1^{\circ} \mathrm{C}$ warmer in the central region of the domain $\left(70^{\circ}-80^{\circ} \mathrm{E}\right.$, $20^{\circ} \mathrm{S}$ ). The increased SST presents a northwest-southeast tilted structure in the central SIO from the equator to midlatitude. The main cause of this enhanced SST during El Niño is due to the decreased surface wind speed [Yoo et al., 2006]. Note that weakened surface wind leads to less evaporation and warmer SST. On the other hand, decreased SSTs are observed in the midlatitude SIO, west of $80^{\circ} \mathrm{E}$, and the west of Australia. The differences in OLR (Figure 3b) are similar to those in SST, representing reduced values (stronger convection) up to $-10 \mathrm{~W} \mathrm{~m}^{-2}$ in the region with the maximally increased SST. The enhanced OLR areas are found in both northeastern (i.e., east tropical SIO) and southwestern (i.e., southeastern Africa) regions with respect to the decreased area. Yoo et al. [2006] suggested that the reduced convection in the east tropical SIO is connected to a weakening of the equatorial westerlies across the Indian Ocean to the western Pacific during El Niño [see Yoo et al., 2006, Figure 5a]. In addition, the weaker convection in 
a) Sea surface temperature

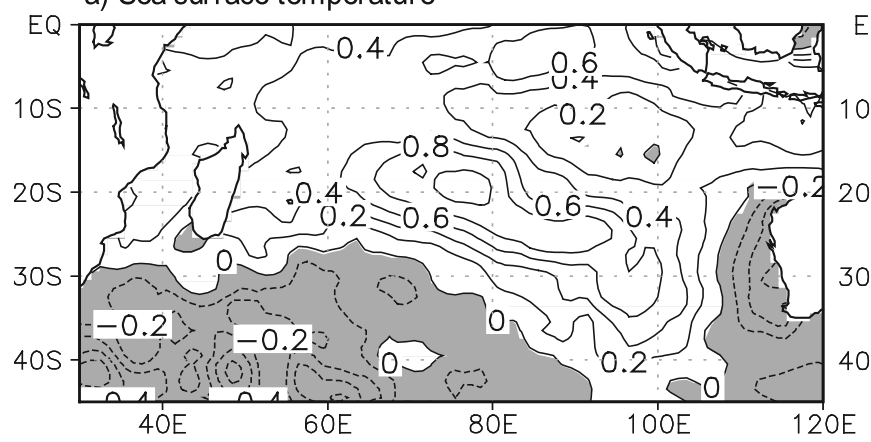

c) 850 -hPa wind

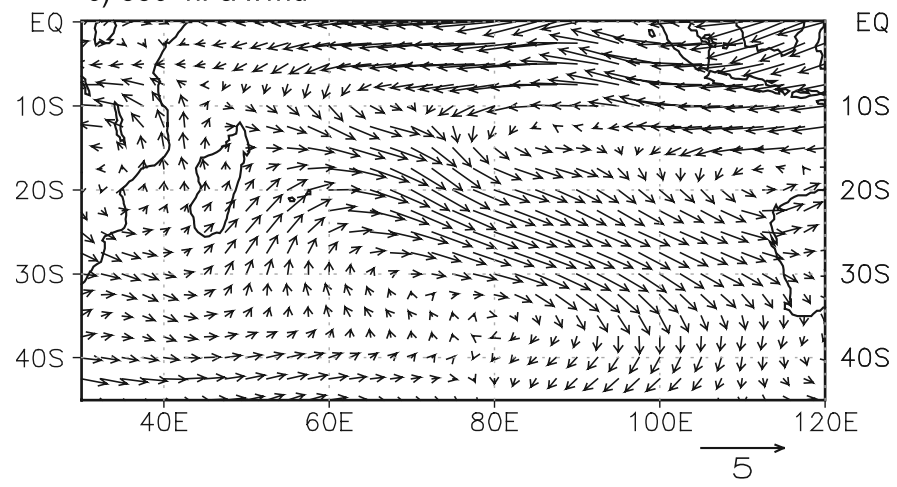

b) Outgoing longwave radiation

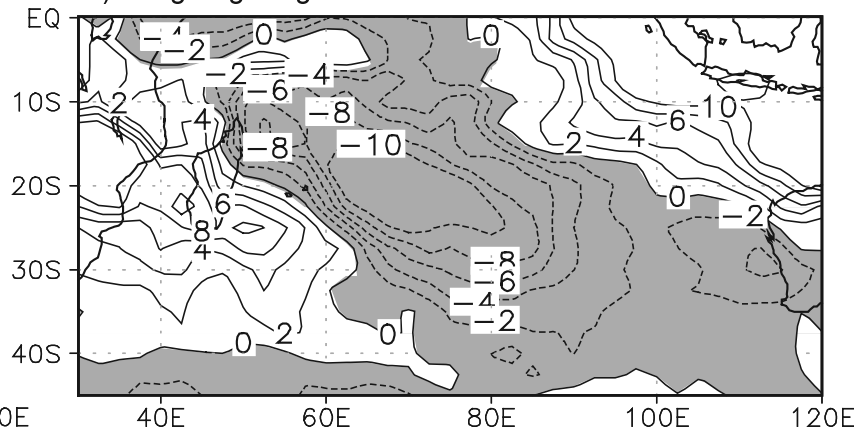

d) $850-\mathrm{hPa}$ relative vorticity

Figure 3. Composite difference fields of (a) SST, (b) OLR, (c) horizontal wind at $850 \mathrm{hPa}$, and (d) relative vorticity at $850 \mathrm{hPa}$ between El Niño and La Niña for the austral summer. The units are ${ }^{\circ} \mathrm{C}$ for SST, $\mathrm{W} \mathrm{m}^{-2}$ for OLR, $\mathrm{m} \mathrm{s}^{-1}$ for wind, and $10^{-6} \mathrm{~s}^{-1}$ for relative vorticity. Negative values are shaded.

southeastern Africa is explained by the $850-\mathrm{hPa}$ anticyclonic anomaly over the region (Figure $3 \mathrm{c}$ ).

[19] Figures $3 \mathrm{c}$ and $3 \mathrm{~d}$ denote differences in horizontal winds and relative vorticity at $850 \mathrm{hPa}$, respectively. As many previous reports have documented, there are massive easterlies along the equator and northwesterlies in the central east subtropical SIO during El Niño periods (Figure 3c). These two large-scale changes produce an anticyclone anomaly centered in the central east tropical $\mathrm{SIO}\left(90^{\circ} \mathrm{E}\right.$, $15^{\circ} \mathrm{S}$ ) and a cyclonic anomaly centered in the central west midlatitude $\operatorname{SIO}\left(70^{\circ} \mathrm{E}, 30^{\circ} \mathrm{S}\right)$. These changes are also consistent with those in the aforementioned OLR and the relative vorticity (Figure 3d). Particularly, the positive vorticity anomalies dominate in the tropical SIO. Note that the positive sign indicates the anticyclonic vorticity anomaly in the Southern Hemisphere.

[20] Combining TC activity and the thermodynamic/ dynamic variables shown in Figures 2 and 3, the westward shift of TC genesis location goes hand in hand with enhanced convection and convergence of $850-\mathrm{hPa}$ winds in the central west tropical $\mathrm{SIO}\left(50^{\circ}-70^{\circ} \mathrm{E}, 5^{\circ}-20^{\circ} \mathrm{S}\right)$ during El Niño compared to La Niña. Overall, the spatial difference in OLR coincides with TC genesis: enhanced convection and frequent TC genesis in the central west tropical SIO versus reduced convection and less TC genesis in the central east tropical SIO. It is interesting to note that the main region of enhanced convection (i.e., negative OLR anomaly) and increased TC genesis is slightly shifted about 20 degree west with respect to the region of increased SST.
That is, the changes in TC genesis do not coincide directly with the local SST changes in the SIO. Rather, these systematic changes in circulation, convection, and TCs require consideration of the large SST changes in the Pacific. These have a remote effect on the tropical Indian Ocean by altering the Walker circulation, suppressing convection during El Niño in a large region, stretching from the east Indian Ocean to western Pacific [Yoo et al., 2006]. The SST increase in the central SIO is also a response to the changes in the large-scale circulation caused by the strong ENSO events.

[21] As discussed above, there are two regions in which a significant decrease in TC passages at the $95 \%$ confidence level occurs during El Niño periods: the central tropical SIO and the southeast of the island of Madagascar. The decrease in TC in the central tropical SIO is related to fewer TC geneses over the region (see Figures $2 \mathrm{c}$ and $2 \mathrm{~d}$ ). However, the reason for TC decrease in Madagascar and surrounding oceans is rather complicated. It may be explained by anomalous southwesterly steering flows east of Madagascar (see Figure 3c). However, TCs are primarily guided by the steering flows averaged over the deep tropospheric layer, rather than the low-tropospheric flows [Chan and Gray, 1982; Kim et al., 2005]. Thus the mean winds of the tropospheric layer have also been examined (figure not shown). The result confirms anomalous southwesterlies in the southeast of Madagascar as well. These southwesterlies lead TCs to recurve early and move farther east forced by 
the midlatitude westerlies. Therefore TC passages increase in the far eastern ocean of Madagascar.

\subsection{MJO Effect}

[22] Bessafi and Wheeler [2006] explored TCs forming in various MJO phases in association with changes in largescale circulation such as vorticity and wind shear over the SIO. On the whole, this study has followed their approach for examining TC genesis location and large-scale circulations. In addition, the authors have tried to link their tracks (i.e., number of passages in the $5^{\circ} \times 5^{\circ}$ grid) to circulation anomaly in various phases.

[23] To investigate the changes in TC activity in relation to the MJO development, the subseasonal variations of TC geneses (with their median) and passages (with their actual tracks) for the total 8 MJO phases are represented in Figure 4. The governing days of each phase are shown in parentheses (next to phase number), which denote the accumulated days for MJO activity stronger than one standard deviation of the MJO amplitudes. The ratio of accumulated days of 8 active MJO phases to the total number of days analyzed is about two thirds (2028 days versus 3025 days). Over the entire domain, in general, most frequent TC activity is observed in phases 2-4, about 10 TCs per 100 days, and less frequent TC activity in the rest of the phases, about 5 TCs per 100 days or less. The ratio of TC numbers for active TC periods to inactive TC periods is about 2, which is similar to previous results [see Bessafi and Wheeler, 2006, Table 1].

[24] In the following section, the authors explain the MJO-TC relation combined with changes in convection and tropospheric circulation focused on phases 2-4 (Figures 4 and 5). The changes from phase 1 to phase 2 are rather dramatic. In phase 2 , the area of enhanced convection expands to the entire tropical SIO and $850-\mathrm{hPa}$ cyclonic vorticity anomalies form southwest of the center of enhanced convection, resulting in a great increase in TC activity during this phase transition. Also the zero line of zonal vertical wind shear is shifted poleward, indicating the retreat of the midlatitude westerly zone. This is also correlated with the increase of TC genesis [e.g., Bessafi and Wheeler, 2006].

[25] Subsequently, the median of genesis location of TC (inverted triangle at the bottom in Figure 4) is shifted east little from phase 2 to phase 3 , corresponding to the eastward propagation of MJO-related convective activity and $850-\mathrm{hPa}$ vorticity anomalies in the central east SIO. However, there is no significant net increase in TC number during this phase transition. Changes in TC passage is also strongly affected by the MJO. As seen from the Figures 4 and 5, more south oriented tracks in phase 3 compared to those in phase 2 are roughly coincident with developing northerly steering wind anomalies in the central subtropical SIO. The northerly wind anomalies are the western branch of the anticyclonic circulation anomalies in the eastern subtropical SIO. These are thought as a part of the off-equatorial Rossby wave response to the suppressed convective activity in the maritime continent, whose existence were theoretically proved via Gill's simple analytic model of the tropical atmosphere [Gill, 1980].

[26] TC tracks in phase 4 become rather west-southwest directed again compared with those in phase 3 , which is caused by the weakened northerly anomalies in the midSIO. When the MJO propagates farther eastward, the convective activity is suppressed over most of the tropical SIO during phases 5-8 and the zero shear line gradually migrates toward the equator. As a result, the frequency of TC genesis is significantly reduced and the passage shows no formulated characteristics. Interestingly, it seems that the TC passage is increased over the east of Madagascar in phase 7. This sudden increase in the number of geneses is just because there are a large number of days (294 days) compared to neighboring phases (i.e., 233 days in phase 6 and 243 days in phase 8 ) rather than systematic variation of the TC passage by the MJO.

\section{Summary and Discussion}

[27] The present study has examined variation of TC activity in the SIO focused on the effects of ENSO and the MJO. Concerning the effect of ENSO (El Niño minus La Niña), the east-west dipole pattern of TC genesis is demonstrated: TCs increase in the western half of the SIO (west of $75^{\circ} \mathrm{E}$ ) and decrease in the eastern half of the SIO (east of $75^{\circ} \mathrm{E}$ ). The ENSO-TC genesis relation is supported by evident decrease in OLR in the central west tropical SIO during El Niño periods. TC genesis is influenced by the changes in large-scale circulation as well. In El Niño periods, there are anticyclonic circulation anomalies in the central east tropical SIO and cyclonic anomalies in the central west midlatitude SIO. These two large-scale gyres constitute a confluent region northwest of the island of Madagascar, causing an increase of TC genesis combined with enhanced convective activity there. It is also found that TC passages are influenced by the ENSO-related large-scale circulation response. The reduced (enhanced) TC passages to the southeast of Madagascar (central midlatitude SIO) are due to earlier recurving of TCs to the east. The anomalous southwesterlies to the southeast of Madagascar during El Niño periods may inhibit the TCs from propagating farther west. Subsequently, TCs are steered by the anomalous northwesterlies between two large-scale circulation gyres, and then decay in the central midlatitude SIO.

[28] In addition, it is found that the variation of TC activity depends on various MJO phases in the SIO: most frequent TC activity is found in phases 2-4 (about 10 TCs in 100 days) while there is less frequent TC activity in the rest of the phases (about 5 TCs in 100 days). The genesis location of TC is shifted eastward from phase 2 to phase 3 , related to the deepening MJO-related convective activity and lower-tropospheric vorticity anomalies. Further, TC passage in the central Indian Ocean seems to be affected by the MJO, which coincides with anomaly patterns of steering winds.

[29] In the present study, the TC best track data from the JTWC is analyzed instead of using the La Reunion RSMC data [cf. Bessafi and Wheeler, 2006]. Although TC numbers are a little different from each other because of different definitions of TC, their temporal and spatial variations are quite similar. To reveal eventual impact of the data used on the result, the authors repeated the same analysis with the La Reunion RSMC data and obtained consistent results.

[30] As a discussion, the Antarctic Oscillation (AAO) is found to be the source of significant large-scale circulation 
Phase 1 (188 days)

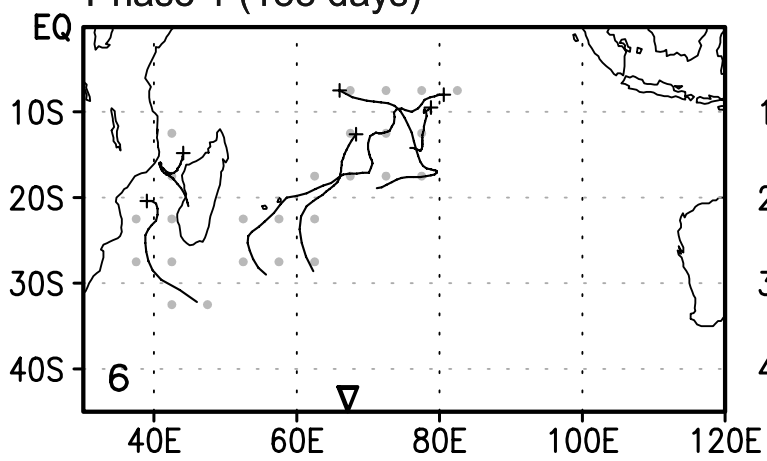

Phase 2 (259 days)

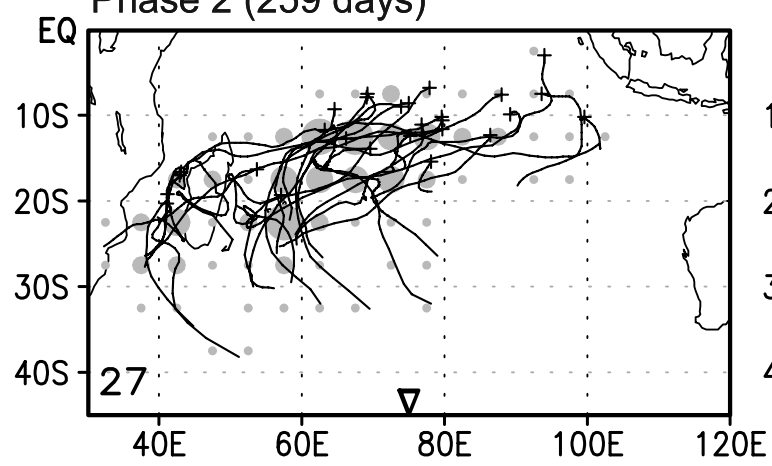

Phase 3 (302 days)

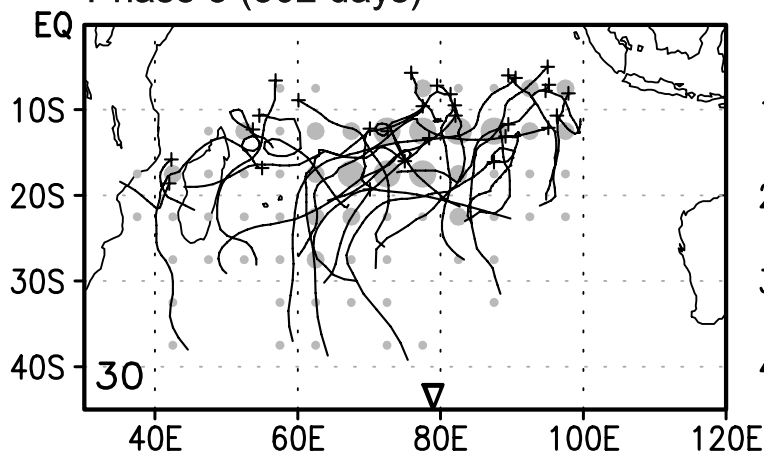

Phase 4 (237 days)

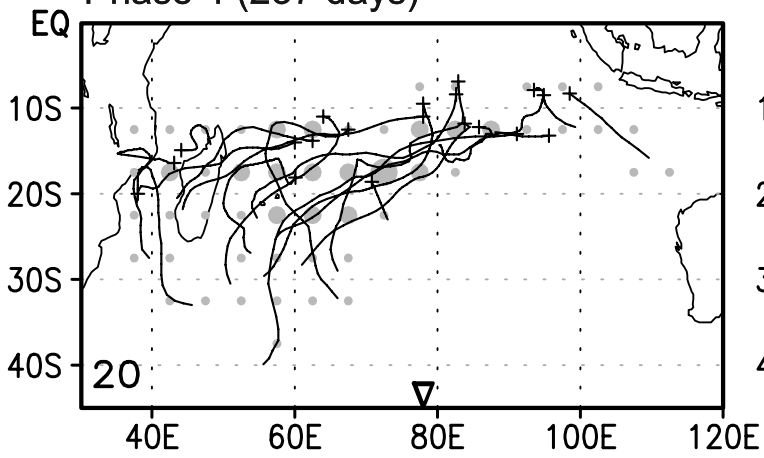

Phase 5 (206 days)

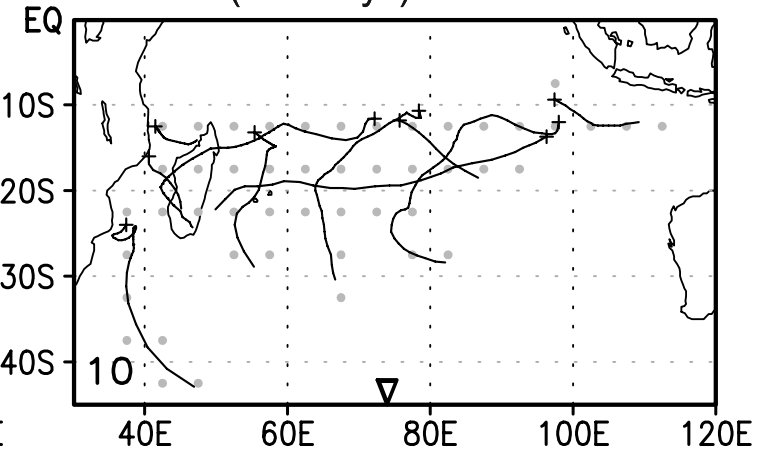

Phase 6 (233 days)

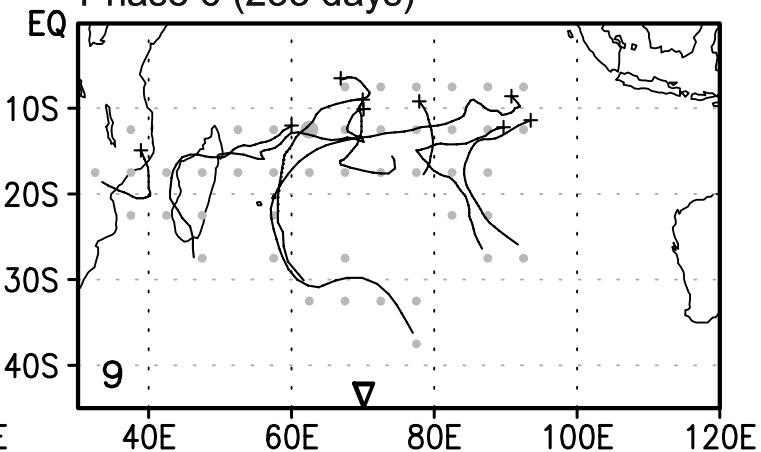

Phase 7 (294 days)

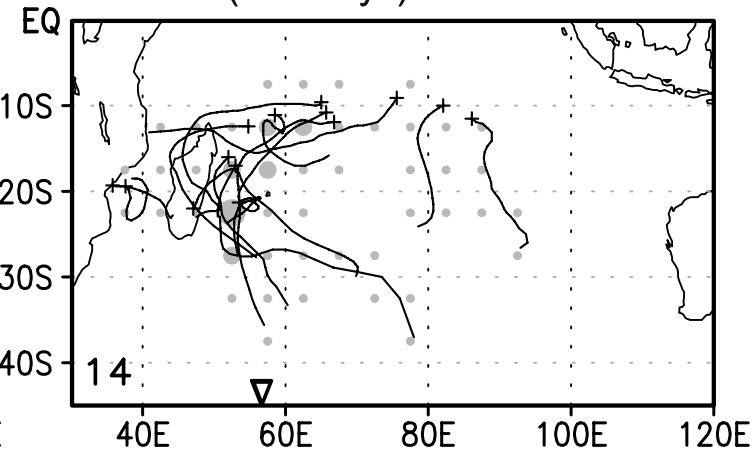

Phase 8 (243 days)

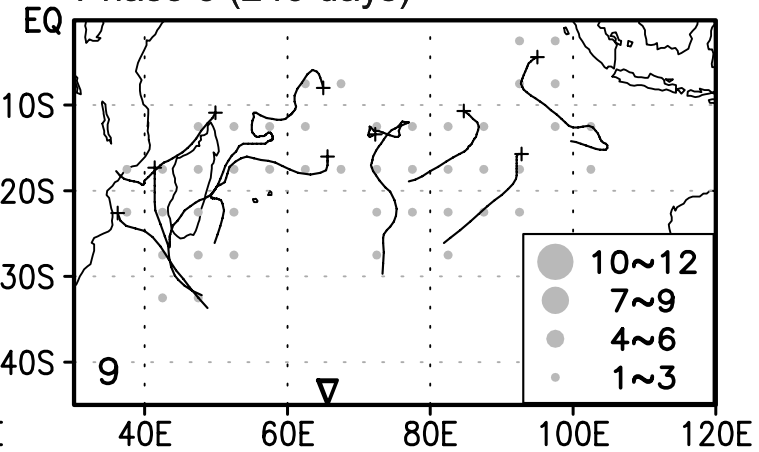

Figure 4. Geneses and tracks of TC for each MJO phase. Pluses indicate the location of TC genesis, and light gray circles denote TC passage numbers in each $5^{\circ} \times 5^{\circ}$ grid box. The inverted triangles are the median of genesis longitude. The governing days of each phase are shown in parentheses, and TC genesis numbers are shown in the bottom left corner for the corresponding MJO phase. 

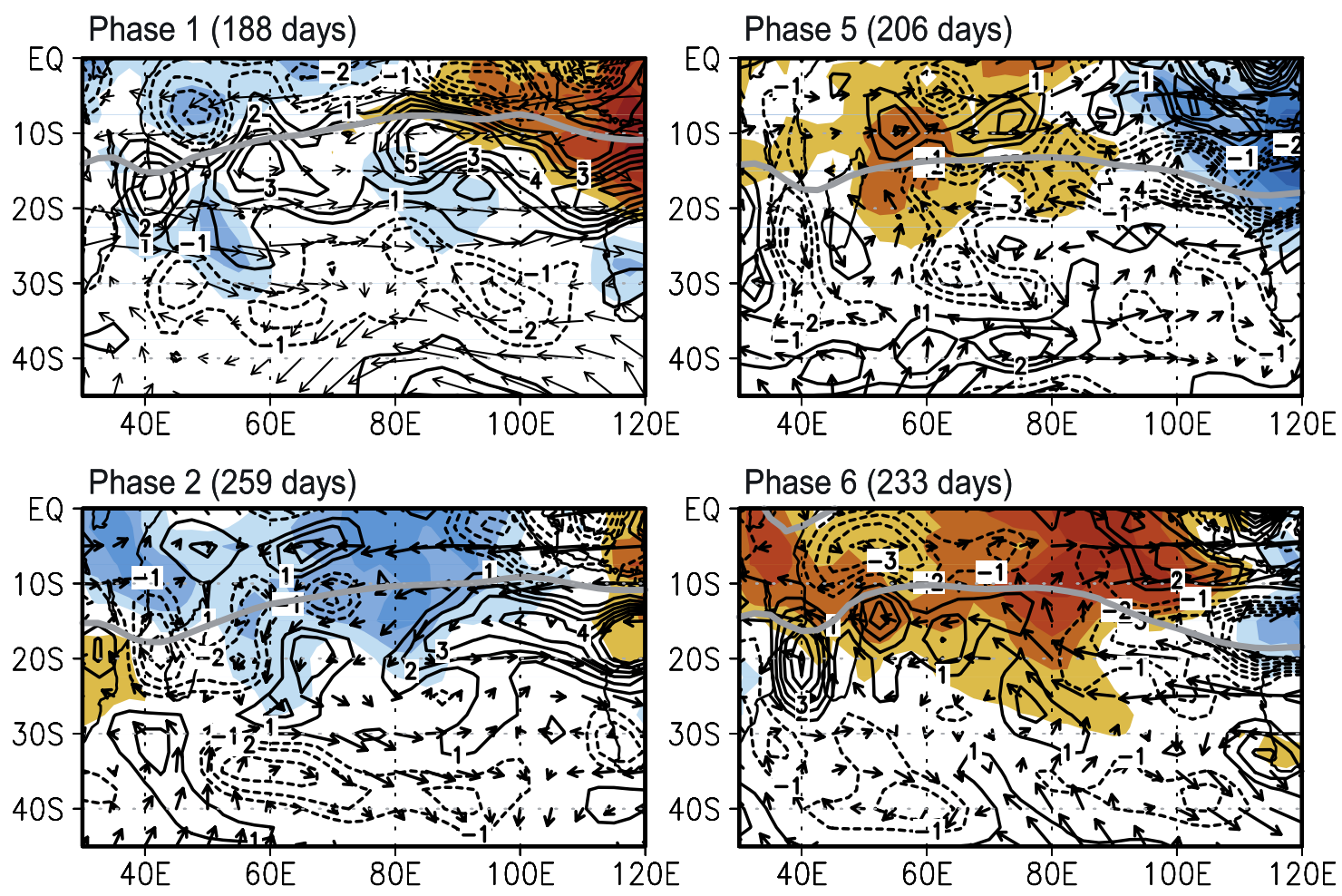

Phase 3 (302 days)

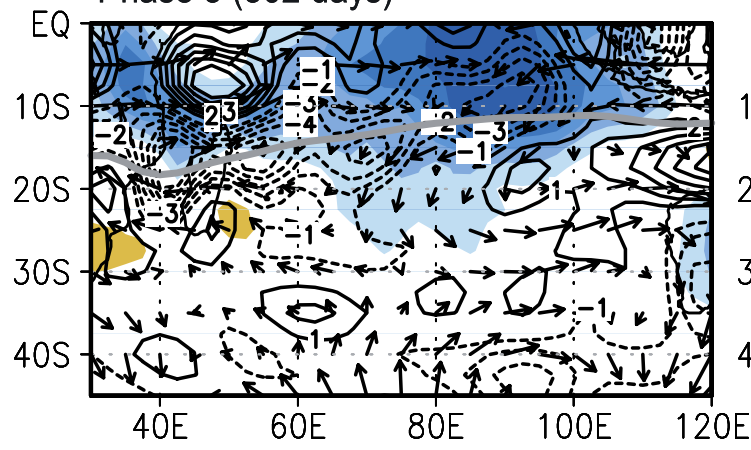

Phase 7 (294 days)

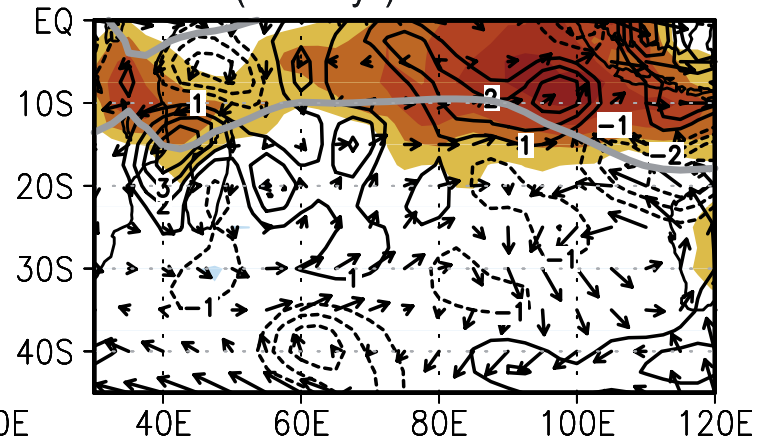

Phase 4 (237 days)

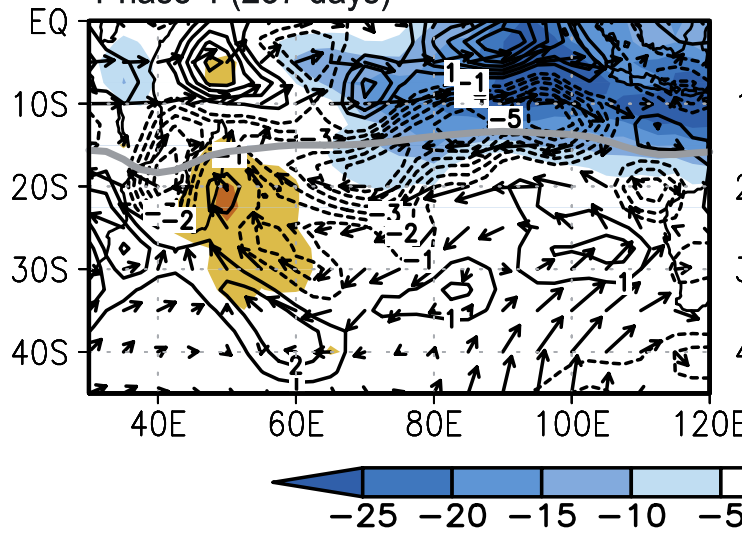

Phase 8 (243 days)

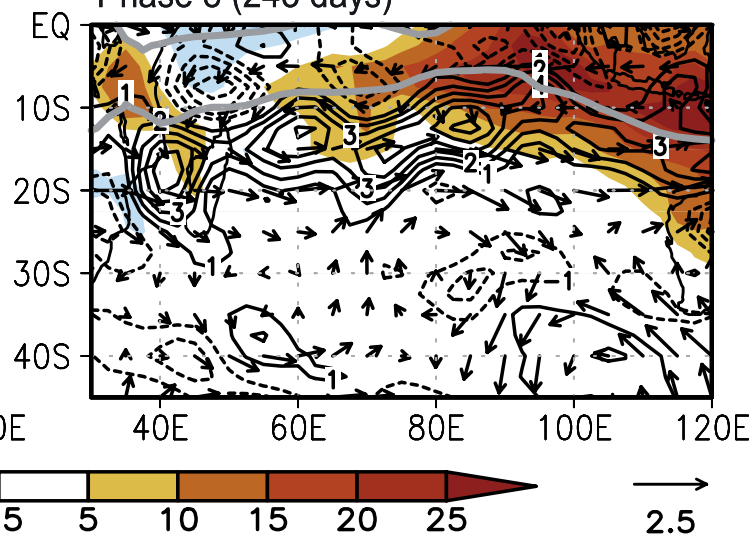

Figure 5. Composite anomaly fields of OLR (shading), 850-hPa relative vorticity (black contours), and mean tropospheric layer winds (vectors) for each MJO phase. Also shown is the zero line of zonal vertical wind shear (thick light gray contour). The units are $\mathrm{W} \mathrm{m}^{-2}$ for OLR, $10^{-6} \mathrm{~s}^{-1}$ for relative vorticity, and $\mathrm{m} \mathrm{s}^{-1}$ for wind and wind shear. Zero contours are omitted in the 850 -hPa relative vorticity. 
modes that extensively modulate subtropical high and jet stream in the Southern Hemisphere [e.g., Thompson and Wallace, 2000], giving a signature in the Tropics [e.g., Thompson and Lorenz, 2004], and interacting with ENSO and the MJO [e.g., Carvalho et al., 2005]. Interestingly, Ho et al. [2005] found the AAO signal in TC variation in the northwestern Pacific across the equator. The TC variation over the SIO in connection to the AAO will be discussed in a separate paper.

[31] This study has explored the interannual and intraseasonal variation of TC activity in the SIO with respect to ENSO and the MJO separately. In addition, it is interesting to examine the modulation of SIO TC activity by looking at the combined effect of ENSO and the MJO. This kind of consideration deals with the scale interaction problem between two phenomena.

[32] Acknowledgments. This work was funded by the Korea Meteorological Administration Research and Development Program under grant CATER 2006-4204. C.-H. Ho is partially supported by Wenner-Gren Stiftelserna while visiting Gothenburg University. The authors are grateful for the critical and valuable comments made by three anonymous reviewers.

\section{References}

Bessafi, M., and M. C. Wheeler (2006), Modulation of south Indian Ocean tropical cyclones by the Madden-Julian Oscillation and convectivelycoupled equatorial waves, Mon. Weather Rev., 134, 638-656.

Carvalho, L. M. V., C. Jones, and T. Ambrizzi (2005), Opposite phases of the Antarctic Oscillation and relationships with intraseasonal to interannual activity in the Tropics during the austral summer, J. Clim., 18, 702718.

Chan, J. C. L. (1985), Tropical cyclone activity in the northwest Pacific in relation to the El Niño/Southern Oscillation phenomenon, Mon. Weather Rev., 113, 599-606.

Chan, J. C. L., and W. M. Gray (1982), Tropical cyclone movement and surrounding flow relationships, Mon. Weather Rev., 110, 1354-1374.

Chu, P.-S. (2005), ENSO and tropical cyclone activity, in Hurricanes and Typhoons: Past, Present, and Potential, edited by R. J. Murnane and K. B. Liu, pp. 297-332, Columbia Univ. Press, New York.

Chu, P.-S., and H. Chen (2005), Interannual and interdecadal rainfall variations in the Hawaiian islands, J. Clim., 18, 4796-4813.

Chu, P.-S., and J. Wang (1997), Tropical cyclone occurrences in the vicinity of Hawaii: Are the differences between El Niño and La Niña years significant?, J. Clim., 10, 2683-2689.

Gill, A. E. (1980), Some simple solutions for heat-induced tropical circulation, Q. J. R. Meteorol. Soc., 106, 447-462.

Gray, W. M. (1984), Atlantic seasonal hurricane frequency. part I: El Niño and $30 \mathrm{mb}$ Quasi-Biennial Oscillation influences, Mon. Weather Rev., $112,1649-1668$.

Hall, J., A. J. Matthews, and D. Karoly (2001), The modulation of tropical cyclone activity in the Australian region by the Madden-Julian Oscillation, Mon. Weather Rev., 129, 2970-2982.

Hartmann, D. L., and M. L. Michelsen (1989), Intraseasonal periodicities in Indian rainfall, J. Atmos. Sci., 46, 2838-2862.

Ho, C.-H., J.-H. Kim, H.-S. Kim, C.-H. Sui, and D.-Y. Gong (2005), Possible influence of the Antarctic Oscillation on tropical cyclone activity in the western North Pacific, J. Geophys. Res., 110, D19104, doi:10.1029/2005JD005766.
Jury, M. R. (1993), A preliminary study of climatological associations and characteristics of tropical cyclones in the southwest Indian Ocean, Meteorol. Atmos. Phys., 51, 101-115.

Jury, M. R., B. Pathack, and B. Parker (1999), Climatic determinants and statistical prediction of tropical cyclone days in the southwest Indian Ocean, J. Clim., 12, 1738-1746.

Kim, J.-H., C.-H. Ho, C.-H. Sui, and S. K. Park (2005), Dipole structure of interannual variations in summertime tropical cyclone activity over East Asia, J. Clim., 18, 5344-5356.

Kuleshov, Y. (2003), Tropical cyclones in the Southern Hemisphere: Influence of the El Niño-Southern Oscillation phenomenon paper presented at 7th International Conference on Southern Hemisphere Meteorology and Oceanography, Am. Meteorol. Soc., Wellington, N. Z.

Kuleshov, Y., and G. de Hoedt (2003), Tropical cyclone activity in the Southern Hemisphere, Bull. Aust. Meteorol. Soc., 16, 135-137.

Landsea, C. W. (2000), El Niño-Southern Oscillation and the seasonal predictability of tropical cyclones, in El Niño: Multiscale Variability and Global and Regional Impacts, edited by H. F. Diaz and V. Markgraf, pp. 149-181, Cambridge Univ. Press, New York.

Lau, N.-C., and M. J. Nath (2003), Atmosphere-ocean variations in the Indo-Pacific sector during ENSO episodes, J. Clim., 16, 3-20.

Liebmann, B., H. H. Hendon, and J. D. Glick (1994), The relationship between tropical cyclones of the western Pacific and Indian Oceans and the Madden-Julian Oscillation, J. Meteorol. Soc. Jpn., 72, 401-412.

Maloney, R., and P. R. Hartmann (2000a), Modulation of hurricane activity in the Gulf of Mexico by the Madden-Julian Oscillation, Science, 287, $2002-2004$.

Maloney, R., and P. R. Hartmann (2000b), Modulation of eastern North Pacific hurricanes by the Madden-Julian Oscillation, J. Clim., 13, 14511460.

Neelin, J. D., D. S. Battisti, A. C. Hirst, F.-F. Jin, Y. Wakata, T. Yamagata, and S. E. Zebiak (1998), ENSO theory, J. Geophys. Res., 103, 14,26114,290 .

Reynolds, R. W., and T. M. Smith (1994), Improved global sea surface temperature analyses using optimum interpolation, J. Clim., 7, 929-948.

Thompson, D. W. J., and D. J. Lorenz (2004), The signature of the annular modes in the tropical troposphere, J. Clim., 17, 4330-4342.

Thompson, D. W. J., and J. M. Wallace (2000), Annular modes in the extratropical circulation. part I: Month-to-month variability, J. Clim., $13,1000-1016$.

Wang, B., and J. C. L. Chan (2002), How strong ENSO affect tropical storm activity over the western North Pacific, J. Clim., 15, 1643-1658.

Wang, B., and H. Rui (1990), Synoptic climatology of transient tropical intraseasonal convection anomalies: 1975-1985, Meteorol. Atmos. Phys., $44,43-61$.

Wheeler, M., and H. H. Hendon (2004), An all-season real-time multivariate MJO index: Development of an index for monitoring and prediction, Mon. Weather Rev., 132, 1917-1932.

Xie, S.-P., H. Annamalai, F. A. Schott, and J. P. McCreary Jr. (2002), Structure and mechanisms of south Indian Ocean climate variability, J. Clim., 15, 864-878.

Yoo, S.-H., S. Yang, and C.-H. Ho (2006), Variability of the Indian Ocean sea surface temperature and its impacts on Asian-Australian monsoon climate, J. Geophys. Res., 111, D03108, doi:10.1029/2005JD006001.

Zhang, C. (2005), Madden-Julian Oscillation, Rev. Geophys., 43, RG2003, doi:10.1029/2004RG000158.

C.-H. Ho, J.-H. Jeong, H.-S. Kim, and J.-H. Kim, School of Earth and Environmental Sciences, Seoul National University, Seoul 151-742, Korea. (hoch@cpl.snu.ac.kr)

D. Chen, Earth Sciences Centre, Gothenburg University, Gothenburg SE-405 30, Sweden. 